\title{
LENGUAJE TEXTIL: UN PATRIMONIO OCULTO A PROPÓSITO DEL TRAJE DEL SEÑOR DE CHIMÚ
}

\section{TEXTILE LANGUAGE: AN OCCULT HERITAGE BY THE WAY OF THE LORD OF CHIMU'S CLOTH}

\author{
Cristina Gutiérrez \\ Universidad de San Martín de Porres, Perú
}

\section{RESUMEN}

A partir del estudio semiótico de un traje ceremonial Chimú, una de las expresiones más completas del textil en nuestra cultura, nos acercamos al discurso en el contenido, desglosando una serie de significados acerca del pensamiento y cosmología de los antiguos peruanos que sobreviven en usos y costumbres de hoy en día en la región de Trujillo.

Palabras clave: Chimú, lenguaje textil, decodificar, etnoagroastronomía, calendario, patrimonio, intangible.

\begin{abstract}
From the semiotic analysis of a Chimu ceremonial costume, one of the most complete textile expressions of our culture, we approach the discourse within it breaking up a series of meanings related to the ancient Peruvian's thinking and their cosmology that are in fact still very much alive in the customs and habits of the Trujillo region modern day inhabitants.
\end{abstract}

Keywords: Chimu, textile lenguaje, decoding, etnoagroastronomie, calendar, patrimony, intangible 


\section{Introducción}

El textil en los Andes ha sido desde siempre el bien más preciado, pues de prenda de vestir pasó a convertirse en objeto ritual, moneda de intercambio, y símbolo de poder. Su desarrollo tecnológico fue parejo al artístico, generando una cadena productiva que se inicia con el cultivo del algodón en la costa y el pastoreo de camélidos en la sierra; sigue con las tareas de hilado y tejido que comienzan en el precerámico y alcanzan su apogeo en los horizontes medios.

El textil es, sin lugar a dudas, no solo el punto de partida de este importante proceso civilizatorio, sino el medio de expresión más intenso en esas sociedades ágrafas que fueron las civilizaciones prehispánicas en nuestro territorio, y seguramente la vía en proceso para lograr un lenguaje formal, prueba de lo cual son los quipus o sistemas nemotécnicos así como los ideogramas llamados tocapus que aparecen en trajes ceremoniales de la etapa inca.

Siendo la cultura andina uno de los seis focos civilizatorios de la humanidad y el único entre ellos que no llegó a poseer una lengua escrita, urge conocer los lenguajes alternativos con los cuales se sostuvo el andamiaje de aquella sofisticada organización socioeconómica que fue el Perú prehispánico. Abordaremos el tema a partir de una pieza textil clave: el traje ceremonial del Señor de Chimú, utilizando la semiótica como herramienta analítica e interpretativa que nos ayude a comprender los sentidos ocultos y la razón de ser de esta pieza. Este análisis inicial es válido en sí mismo pues nos abundará sobre el contenido del traje como soporte de significaciones, pero iremos más allá, lo seguiremos auscultando en la búsqueda del hilo conductor que nos contextualice ese traje perteneciente a nuestro pasado cultural, con el presente, que nos ayude a abordar y ver con ojos distintos hechos de nuestra realidad cotidiana, a preguntarnos sobre cuánto de aquello pervive entre nosotros, a reconocer nuestra identidad desde diversos ángulos. Arnold y Espejo (2013), desde la vecina Bolivia se adentran en el lenguaje textil considerando su natura «tridimensional» como ente comunicador ampliando sus significados más allá del ámbito técnico e iconográfico para incluir el entorno sociocultural:

¿Qué implica esta tridimensionalidad del textil? ¿qué tiene que ver esta tridimensionalidad con los aspectos técnicos y tecnológicos del textil? y ¿qué tiene que ver esta tridimensionalidad del textil con la idea del textil como un ser viviente en proceso de desarrollo? En resumen: ¿cómo podemos expandir nuestro horizonte desde un entendimiento de lo superficial del textil a entender con mayor profundidad sus nexos con los objetos y sujetos de su entorno? (p. 49)

En el proceso de adquisición de la escritura por parte de las civilizaciones, las sociedades buscan organizarse a través de almacenadores de información, los que a su vez se tiene que manejar con códigos reconocibles que puedan ser entendidos por el resto, por los receptores del mensaje. Gabriela Núñez, experta en oralidad y escritura señala:

Gaur sostiene que no hay escrituras primitivas, precursoras de la escritura, ni escrituras de «transición» propiamente dichas, sino sociedades en un determinado nivel de desarrollo económico y social que utilizan determinadas formas de almacenamiento de información. Si una forma de almacenamiento cumple con su objetivo hasta donde una determinada sociedad le pide, resulta ser -para tal sociedad concreta- una «escritura propiamente dicha». (Gaur, 1990, citado en Nuñez, 2015, p. 20) 
Y eso es lo que debe quedar claro para todos. ¿Cómo entonces se organizan estos códigos, estos símbolos para que cumplan su cometido? ¿Cómo se organizaron en el antiguo Perú? Si bien es cierto que en el Perú prehispánico existían muchas lenguas, se compartía una forma de ver el mundo, una forma de organizar el pensamiento y una forma de registro de datos por referencia directa y por representaciones simbólicas ceremoniales ligadas a eventos y acciones compartidas por el grupo. El espacio, el tiempo, el ritual son imprescindibles para que esta comunicación se lleve a cabo. Exploraremos ese horizonte cultural a través de esta prenda en pos de claves de un pensamiento aparentemente extinto, pero que sobrevive en particulares manifestaciones presentes en el actual Trujillo como son las festividades de la Virgen de la Candelaria del Socorro en Huanchaco. Al mismo tiempo, exploraremos un viejo camino ritual chimú para conocer el posible recorrido del Señor de Chimú, y gracias al calendario agrícola por el que supuestamente se rigió, nos aproximaremos a la fecha en que ese ritual tenía lugar.

\section{Ubicación y contexto histórico}

El reino de Chimú se desarrolló en la costa norte del Perú, durante el periodo denominado Intermedio tardío, entre el 1100 y el 1470 d. C., entre los valles de Chicama, Jequetepeque y Zaña por el norte y Virú, Chao y Santa por el sur, llegando en su momento de gloria hasta Tumbes, mucho tiempo después que la refinada civilización moche que los precedió hubiese colapsado, y aunque no son sus herederos directos, comparten mucho. La capital de esta civilización fue Chan Chan, al centro de la cual estaba la ciudad prohibida que resguardaba detrás de sus muros y su única puerta, varios templos con enormes patios ceremoniales, uno para cada uno de los diez reyes que constituyeron la estirpe. Suponemos que el traje perteneció a alguno de ellos. El reino de Chimú siempre ha sido mirado bajo la lupa de sus antecesores moches, y en ese sentido y de manera discutible, le restan grandiosidad, pues aunque sus palacios están decorados con gran iconografía, esta no muestra la sofisticación de los moches. Lo mismo diríamos de su cerámica, bastante pobre, siempre comparándola con la de sus antecesores.

Sobresalieron sí, y de manera notable, en la orfebrería y en el textil. El Chimú fue un reino de la abundancia, de paz y prosperidad que generó una gran cantidad de artesanos diestros en trabajos en madera, orfebrería, cueros, y sofisticados textiles en su estructura, en su diseño y en la confección de complejos vestuarios que implicaban trabajo de hilanderos, tintoreros, plumareros, tejedores y costureras. Tal esplendor no sobrevivió a la conquista inca. Para cuando llegó Pizarro en 1470, la ciudad, en gran parte abandonada, era ya un pálido reflejo de lo que había sido.

Conocido también, como el Reino del Gran Chimú su estructura social estaba centrada en un poderoso señor y su jerarquía eclesiástica; encargados no solo del manejo de sus súbditos, sino del complejo entorno geográfico y ambiental ubicado en un desierto costero dependiente de la corriente del niño, catastrófica y benefactora al mismo tiempo, pero el verdadero amo y señor de la agricultura y pesca. Ellos, la casta gobernante, eran los encargados de predecir este ciclo climático, y en todo caso de interceder ante estas fuerzas superiores por la abundancia y la prosperidad. 
Hoy, allí donde se desarrolló esta civilización, se encuentra la próspera ciudad de Trujillo, donde la modernidad se cruza con una fuerte raigambre de origen español. Ciudad criolla emblemática de la costa peruana con su particular estilo arquitectónico de clara influencia hispana, oculta sin embargo, tradiciones de antiguo origen que la población mantiene celosamente. Tierra de chamanes y curanderos, ha cruzado creencias originarias con las que la iglesia católica impuso, creándose un vínculo entre ambas tradiciones, sin que los mismos pobladores puedan explicarse por qué se dieron así. En este contexto, el estudio de un traje ceremonial chimú examinado como testimonio del arte textil prehispánico, nos dará la pauta para decodificar sus contenidos y desentrañar los hilos que lo atan al presente.

\section{El traje del Señor de Chimú}

El objeto del presente estudio es el traje de tres piezas de un poderoso señor chimú, conservado casi intacto, actualmente pieza central de la colección textil del Museo Chileno de Arte Precolombino de Santiago fundado en 1981 con la donación de la colección privada del arquitecto Sergio Larraín García-Moreno, quien fuera embajador de Chile en el Perú entre los años 1960 y 1970.

Ubicando el traje, diremos que la primera mención oficial que de él se hace en el Perú es en la publicación Tejidos Milenarios del Perú, en el artículo de Ann Rowe Pollard Textiles Chimú y aunque de él hace una somera descripción, nos explica su origen así:

El más temprano de estos estilos, en base a sus diferencias, lo he llamado el estilo del Lote Bird. Es llamado así en honor al arqueólogo Junius Bird (1907-1982), durante muchos años curador de Arqueología Sudamericana en el American Museum of Natural History de Nueva York, quien registró un número grande de estas piezas cuando recién aparecieron en el mercado del arte en 1957-58 (el subrayado es nuestro).

Aclarando posteriormente ...

El conjunto de la lámina 5 (nuestro traje en mención) parece ser contemporáneo del lote Bird, aunque no se dispone de ninguna información de su historia, salvo que actualmente se encuentra en el Museo Chileno de Arte Precolombino de Santiago. El traje no solo está decorado con borlas, sino también con pequeñas esculturas de hilo, representando varias plantas que incluyen tubérculos, flores de maíz masculino, flores de coca, bolas de algodón y otras difíciles de identificar. Estas esculturas se proyectan tanto de los redondeles rojos como de los cuerpos de pequeñas figuras humanas de perfil en tejido tapiz que usan un gorro con rayas que les cuelga por detrás. La inserción no tiene las borlas de plantas. Algunos fragmentos con borlas de plantas fueron encontrados con el lote Bird (se dice que son de un gran tapiz de pared), confirmando la posibilidad de alguna relación. (Rowe, 1989, pp. 446-448)

Unos años antes Julie Palma e Isabel Baixas (1986) en un breve artículo en la revista Chungara nos precisan datos acerca de una pieza que podría ser una estola (¿o el tapiz de pared?) parte del conjunto, mencionada por Rowe, que se encuentra en el Museo de Seatle y otra pieza de similar textura en el Museo del Hombre en París, que también posee las aplicaciones consideradas desde ya excepcionales en su género. Luego, Reid (1988) a su vez afirma (aunque sin mencionar nuestro conjunto): 
El descubrimiento más trascendente de estos conjuntos o combinaciones chimú parece haber acontecido por los años 1950. Subsiguientemente fueron estudiados y analizados por el reputado arqueólogo norteamericano Junius Bird, curador de arqueología de América del Sur en Nueva York. (p. 146)

En Lima, en el Museo Amano existe otra pieza de la misma familia, una camisa casi idéntica a la de nuestro traje, pero sin las aplicaciones. Sorprende, eso sí, que el traje objeto de nuestro trabajo sea único en su género, y sin lugar a dudas es la pieza textil prehispánica por excelencia, por varias razones: porque su estado de conservación es excelente, porque constituye prácticamente el único espécimen de esta categoría que se mantiene como atuendo completo (turbante, faldellín y camisa cosidos a mano para obtener su forma), por su belleza misma y finalmente por la compleja confección que contiene toda una simbología que vamos a descubrir, y que gracias a la datación en carbono 14 sabemos que la fecha de su confección fue entre el 1320 a 1440 d. C., amplio margen, que solo nos habla de una etapa de esplendor e independencia chimú previa al dominio inca. Eso es todo.

Sucede sin embargo, que el poder de este traje sobrepasó su mero atractivo estético y despertó la curiosidad de investigadores chilenos que comenzaron a sacudirlo de su sueño de siglos. En 1997, precisamente un grupo de investigadores chilenos, Paulina Brugnoli, Soledad Hoces de la Guardia, Paulina Jelvez y Tania Gomez, hacen un acotado e interesante estudio en torno a la estructura textil del traje que publican bajo el título Fertilidad para el desierto. Un traje ceremonial chimú. Costa norte de los Andes Centrales, siglos XII-XV, en el cual avanzan también con el trabajo iconográfico identificando algunas de las plantas bordadas. Pero, es recién en el 2006 que el Museo Chileno de Arte Precolombino de Santiago en colaboración con el entonces Instituto Nacional de Cultura del Perú y el Proyecto Huacas del Sol y la Luna de Trujillo, hace un minucioso trabajo de restauración y publica Laberintos de un traje sagrado (2005-2006), documento invalorable para realizar un trabajo como el presente. Seducidos por su belleza y alto contenido estético, los expertos estudiosos del Museo chileno han llamado a este traje poéticamente «metáfora de un jardín en el desierto», y aunque compartimos la admiración de nuestros vecinos por la pieza, hemos vulnerado ese espacio estético para analizarlo semióticamente, a través de la decodificación de sus estructuras técnicas y materiales y los significantes que nos descifraran el meta discurso allí construido. Este impecable documento aunque incompleto en su análisis, nos permite adentrarnos en las técnicas y materiales usados, así como en su detallado contenido iconográfico. Sin embargo, no nos ha sido posible visitarlo personalmente.

Aclararemos además, que nuestros propósitos no son ni arqueológicos ni históricos sensu stricto, buscamos más bien nuevas fórmulas epistémicas de aproximarnos a nuestro pasado de una manera multidisciplinaria. Desde esta perspectiva, el análisis semiótico de los contenidos del traje nos llevarán a descubrir una forma de pensamiento, de ver el mundo y de concebirlo que no pueden ser medidos con las estructuras occidentales a las cuales estamos acostumbrados, pues se trata de parámetros culturales ancestrales del mundo andino que aún permanecen en nuestro inconsciente colectivo y forman parte de nuestra identidad actual, de eso que llamamos pensamiento peruano, nuestro patrimonio inmaterial, no tangible. De allí su importancia en descifrarlo. 


\section{La lectura del texto}

Le daremos al traje un tratamiento de texto para decodificarlo. Consideraremos el corpus textil como una gramática donde se organizan sintácticamente los significantes a partir de los siguientes elementos y niveles de su proceso constructivo:

1. La fibra usada es mixta, algodón para el tejido base reticulado y alpaca para las estructuras flotantes y superpuestas. La hilatura de algodón en un color pardo claro natural, responde a un patrón de uso propio de la costa en que las mujeres hilan sentadas y recogen el hilado de un una torta de algodón pegada a un punto fijo, mientras que las mujeres de las alturas hilan caminando. La torsión del algodón, se hace de un solo cabo torcido en «S» para la trama y para la urdimbre son de dos cabos, de torsión fuerte en dirección «Z». En lo que corresponde a la fibra de camélido para todas las estructuras flotantes y de colores fuertes, es de alpaca, hilado fino suelto de dos cabos y de torsión floja en dirección « $2 \mathrm{~S}$ » como es de uso en la sierra. Hasta acá estamos ante un patrón usual de hilado chimú. Es casi seguro que el hilado de alpaca fuese importado ya hecho de la sierra.

2. Los colores del hilado de alpaca, a diferencia de los hilados de algodón que conservan su color café claro natural, se tiñeron con pigmentos naturales consiguiendo al menos 20 tonos diferentes. Siempre fue así porque pues el algodón no tiñe bien en tanto que la alpaca sí. La camisa es la prenda que ostenta la mayor variedad de colores, mientras que los tonos y matices de rojos son más abundantes. No creemos que existan significados especiales en estas variaciones por ser condiciones de un teñido artesanal.

3. El tejido base es un reticulado de algodón que es la estructura primaria sobre la cual van las aplicaciones. El algodón solo fue usado en la costa como vestimenta por las condiciones climáticas cálidas, pero en la sierra es utilizado como urdiembre por tener mayor rigidez que la alpaca que por ser sedosa es elástica y tiende a soltarse y a desgastarse con la frotación. Este reticulado es una tela calada sobre la cual van las aplicaciones en secuencias que conforman cuatro estamentos: el calado o red, el bordado de las cruces superpuesto a la red, las aplicaciones de círculos y de danzantes, luego vienen las miniaturas de flores y la borlería que no llegan a cubrir el calado al $100 \%$ y permiten una cierta transparencia.

4. La iconografía. El diseño de los rectángulos divididos en cinco cuadrados conteniendo la cruz chacana sobre la cual se ha colocado un círculo o espejo de agua, los personajes y los doce tipos de plantas.

5. La confección. Los mochicas y los chimús son los únicos que no usan túnicas o uncus, sino dos piezas como atuendo, el faldellín o taparrabo, y la camisa, ambos han necesitado de confección para coserle al faldellín la tela que va en contacto con el cuerpo, y a la camisa las mangas. El tocado también requiere de una juntura.

Todas estas etapas de superposición han requerido de un elaborado procedimiento: la primera estructura es un tejido plano calado hecho en algodón color pardo, formando un reticulado anudado finamente y elaborado tipo red. La segunda estructura es una faz de trama donde se interviene con alpaca de color rojo combinándose con amarillo ocre con que se va coloreando la prenda y que delimitan espacios rectangulares. 
La tercera estructura son aplicaciones de círculos colocados en posición opuesta a la de los personajes, usando algodón como urdimbre, y tejidos en faz de trama con fibra de camélido.

La cuarta y última estructura son las terminaciones que rematan la composición del tejido: aplicaciones y volumétricas que bordean los motivos o en el perímetro de los diseños principales y son de dos tipos:

- Las borlas hechas con fibra de camélido teñidas de color rojo. Las hay únicas o en grupos, simples, triples o complejas, dependiendo de la decoración y van aplicadas al tejido con costura: las principales son las triples que rodean el perímetro de los rectángulos y bordes de las cruces. Las borlas complejas son manojitos de borlas simples eslabonadas por cordoncillos a borlas de dos capas que a su vez albergan a borlas más grandes. Veremos que las simples ocupan las bases de ciertos lugares, las complejas todos los perímetros y las múltiples solo están en la parte central del faldellín, pero no tenemos más detalles que nos permitan aplicar criterios numerológicos para interpretar estos elementos. Su función es doble: mantener oculto el contenido de las plantas y decorativa.

- Los volúmenes tejidos o miniesculturas de elaboradísimo diseño pertenecen a 12 plantas cuya confección ha implicado una variedad de técnicas, ellas a su vez tridimensionales que les otorgan un volumen casi escultórico (embarrilado, anillado, ovillado, trenzado plano, punto festón y otros) buscando representar lo más cercanamente a la planta en su estado natural.

Conocidas las cuatro estructuras superpuestas que constituyen el entramado del traje, pasemos a describir su decorado: Se trata de 24 paneles rectangulares en la camisa (12 en frente y 12 en el dorso), 32 paneles en el faldellín y 12 paneles en las bandas laterales del turbante (68 en total) sobre los cuales vienen las aplicaciones que son ya el diseño mismo. Estos rectángulos a su vez están divididos en tres partes: dos pequeños cuadrados en la parte superior y dos en la inferior conteniendo el de arriba un círculo a la izquierda y un personaje a la derecha, situación que se invierte en la parte inferior. El centro es un cuadrado mayor en cuyo centro hay un miniplano arquitectónico en forma de cruz escalonada (68 en total), claramente espacios ceremoniales en forma de cruz cuadrada chakana o chakata (representación de la constelación andina Willka Chakata), con un círculo en el centro. Este cuadrado central contienen cuatro personajes con una vara, dos arriba y dos abajo, guardianes de cuatro esquinas que miran en direcciones opuestas.

Tenemos entonces, que cada panel está dividido en cinco cuadrados, esto es 340 cuadrados, y contiene seis personajes por panel, lo que nos da un total de 408 personajes, tres círculos por panel, lo que hace 204 círculos y 68 chakanas. Cada personaje y cada círculo tienen aplicados encima una planta, esto es 9 plantas por panel, total de 612 plantas, respecto a las cuales solo sabemos que se trata de doce elementos agrícolas, faltando información acerca de la cantidad de cada una de ellas y el balance de su distribución a lo largo de la tela, que nos marcarían una pauta jerárquica más acotada para completar con mayor aproximación esos significados.

Descrita la estructura de la tela y la confección del traje, pasaremos a estudiar cómo se van conformando los significados desde cuatro variables: 
1. Iconográfica. El hombre del báculo (en realidad es un instrumento agrícola convencionalizado en báculo para los rituales) es el oficiante (está vestido con el traje), y se halla ubicado en el extremo izquierdo superior teniendo enfrente el círculo u ojo de agua, generalmente una concavidad que a manera de espejo reflejaba el sol durante el cenit (mediodía), el momento máximo del ritual. Valladolid (1993) hace un extenso análisis al respecto:

En 1934 Luis E. Valcarcel redescubrió en la parte alta de Saycayhuamán una construcción redonda que en realidad era un almacén de agua pura, llamado Muyucmarca (en quechua «lugar redondo»), lugar ceremonial que cumple las mismas funciones que los ojos de agua, pero elevado a su máxima potencia y fue usado como calendario agrícola. Excavaciones recientes conectan este complejo con un camino ritual (no tiene características de Capac Nan) que lo conectan a la cercana laguna de Cochapata. (pp.171-207)

El eje central, la chakata, distribuye direcciones, roles y momentos. Las plantas (12 variedades) están superpuestas (sembradas) sobre cada uno de los cuadrados (inclusive sobre los personajes) y la única indicación que tenemos en nuestro documento de estudio, es la referida a los tubérculos, los que ocupan los espacios menores de los rectángulos, que nos habla de su menor jerarquía nutricional. Basándonos en los dibujos hechos por el museo chileno, y en conocimiento de la producción del ecosistema costero de suelos ricos y clima templado de $20^{\circ}$, tenemos: una escultura de algodón (la escultura mejor lograda) planta fundamental para la vestimenta, una de coca, planta ritual y sagrada, una de camote, tubérculo de ciclo corto y hasta tres cosecha al año, dos versiones de maíz, planta fundamental en la alimentación y bebida con dos siembras al año expresado en flor y fruto, inflorescencia macho y hembra, cuatro tipos de leguminosas de ciclo corto, propias para la siembra temprana y cosecha a los seis meses: ají, caiguas, pallares y maní, y tres tipos de árboles frutales: palta, chirimoya y lúcuma con cosechas anuales pero de larga vida y productividad. La identificación de las plantas no fue tarea fácil, está basada en los dibujos del documento del museo y fueron analizadas por el etno botánico Dr. Roobert Jiménez quien asoció su ciclo de crecimiento, lugares de origen, refrendos históricos con el ciclo agrícola mencionado por el Ing. Valladolid, cruzando las semejanzas con importancias nutricionales e implicancias de ciertos cultivos propios de la zona.

2. Numerológica. En esta tarea nos acompañó el ingeniero Julio Valladolid, experto en una rara especialidad que llamaremos etnoagroastronomía producto de muchos años de pacientes observaciones e intercambio de saberes con los agricultores de todo el país, que correspondería a la lectura de los astros para elaborar un calendario agrícola, dividido de acuerdo al movimiento del sol en ocho recorridos en el horizonte este y ocho en momentos de la luna andina que es opuesto al sol: el sol camina por la derecha y la luna por la izquierda pues son opuestos complementarios. Esto nos da doce lunaciones al año y ocho posiciones del sol que determinan los ocho momentos del calendario agrícola: primera siembra, siembra grande de granos, siembra grande de tubérculos, aporque, cosecha de la primera siembra, barbecho, cosecha de siembra grande y almacenamiento y selección de semillas, que a su vez están marcadas por cuatro momentos astronómicos en el camino del sol en el horizonte este en sus cinco posiciones: solsticio de junio, sol de nadir en agosto, equinoccio en setiembre, sol cenit en octubre y el solsticio de diciembre, así como los cuatro movimientos de la luna andina en su recorrido de ida y cuatro en los de vuelta. El eje de toda esta 
movida se da teniendo como centro la «constelación» de la cruz cuadrada o Huillka Chakata en los cielos, cuya presencia iconográfica aparece desde los inicios de nuestra civilización en Chavín, Tiawanaku e Inca solo para mencionar las principales, y que como toda la iconografía mencionada se ve marcada en el traje con el manejo del número cuatro y sus múltiplos: cuatro estructuras de tejido, 68 paneles rectangulares, 68 cruces cuadradas, 204 círculos que serían fuentes o espejos de agua, 408 personajes, 12 variedades de plantas que hacen un total de 816 , faltándonos lamentablemente información acerca del número exacto y distribución de cada una de ellas. Hacemos la salvedad por las razones ya explicadas, que no hemos estudiado la numerología de las puntadas que contiene el contorno de las cruces y de otros componentes también contenedores de significados. Campana (2012) estudioso de la numerología chimú en sus monumentos arquitectónicos hace una especulación aproximativa que no se atreve a confirmar:

Hace más de 2 años hicimos un breve estudio de las imágenes del templo de Arco Iris, advertimos que hay cantidades recurrentes, las que se agrupan siempre a partir de conjuntos menores, uno de 2 y 2 para conformar un 4, otro de 2-1-2 conformando un 5 y un tercero de 3-1-3 sumando siete, que cuatro veces siete se obtiene 28 , cifra correspondiente al mes lunar. De estas tres cifras se abrían tres posibilidades para llevar a otras cifras mayores y al final se llegaba a la de 364 correspondiente al mes lunar de trece meses. (p. 55)

3. Direccionalidad. La lectura iconográfica prehispánica tiene sus pautas, establece una sintaxis que como ya dijimos es numérica y direccional, definiendo los valores a través de las combinaciones de ambos: horizontal, vertical y diagonal en doble dirección que debieran guiarnos hacia su propia episteme. No nos arriesgaremos a tanto, por muy seductor que resulte, a establecer nexos entre la estética o modalidad estilística del traje y las significaciones simbólicas que contiene. En este caso queda claro que el eje de la composición es la cruz andina o chakata que marca el arriba y el abajo (lo conocemos mejor dentro de los 4 conceptos incas: Uku Pacha o mundo de abajo, mundo de los muertos, Hanan Pacha o mundo de arriba, Kai Pacha, mundo de aquí y Hakak Pacha, mundo del más allá) y alrededor de la cual giran todos los astros, que es la constelación que aparece alrededor del primero de noviembre (Todos los Santos) y marca la primera siembra. A partir de su aparición se inicia el calendario agrícola que sigue en su secuencia de fechas en agosto con la llegada de las primeras aguas a los canales, y culmina con la cosecha de esta siembra temprana a mediados de febrero. La siembra temprana es la fecha clave pues los primeros frutos a cosechar son los más importantes, los que deben ser entregados a la divinidad, y por tanto, la fecha ritual por excelencia para este tipo de ceremonia tendría que ser febrero (carnavales). La posición de los personajes que rodean la cruz de espaldas a ella señala los cuatro puntos cardinales hacia donde dirigen sus miradas. Los personajes del arriba y el abajo se relacionan en diagonal de manera de contrarios complementarios conformando así un patrón complejo de orden, pues aunque ambos dirigen la mirada en la misma dirección, en la composición discursiva, el de la esquina superior derecha mira el ojo de agua, y el de la esquina inferior izquierda le da la espalda, ambos dirigidos hacia el poniente, como indicando el ciclo de la naturaleza: el tránsito de las aguas dulces al discurrir hacia el océano para enriquecerlo, y a su vez las aguas del mar evaporándose en nubes hacia los Andes para regresar a él convertidas en ríos. Existe además un juego de posición de los pies no descrito con precisión en el documento, que indicaría que los pies de los seis personajes van en el mismo sentido que su mirada. 
4. Cromática. El increíble manejo de tintes en el antiguo Perú fue hecho solo con fines rituales y para la élite: una tecnología tan exquisita y sofisticada no podía ser hecha a gran escala. Los colores tienen códigos bien claros, y de manera genérica diremos que desde siempre, y aún ahora en el textil, el rojo expresa tierra y sexualidad, es decir fertilidad, y que el amarillo se vincula con la producción agrícola. Detectamos color blanco alrededor de la chakata, pero no contamos con mayores referencias, así como de otros que quizás puedan existir.

\section{Ampliación del campo textual: Trujillo hoy}

Hemos desagregado el texto, lo hemos ubicado en su contexto histórico enmarcado en su cosmovisión propia. Ahora ampliaremos nuestros referentes hacia el presente para encontrar significantes que validen estas hipótesis, para lo cual nos referiremos primero a los estudios arqueológicos sobre los caminos rituales chimús. La red vial chimú de uso público fue amplia y ciertamente anterior a la inca, pero dentro de ella existe un camino en particular ya ubicado años antes por Rodríguez (1970), como saliendo casi paralelo al muro exterior de la ciudadela Laberinto hacia el oeste hasta llegar cerca de la orilla del mar y hacia el este hacia el Cerro Cabras allí donde se juntan los canales de irrigación. Valle (2010) precisa:

Ubicado en la margen derecha del río Moche, con un recorrido aproximado de $9 \mathrm{~km}$ de largo y un ancho promedio de $14 \mathrm{~m}$, permite el desplazamiento del hombre desde la orilla del mar hasta el canal Milagro Alto o AL que se forma por la intersección de los canales La Cumbre y Vinchasao (irrigaciones chimus) (...) en las faldas del Cerro Cabras, en donde actualmente se encuentra el local del Pronaa. (km 558 de la Panamericana Norte). (p. 76)

Este camino así depredado ya no es fácil de recorrer completo, hoy sin embargo, es fácilmente reconocible por todos gracias al enorme cartel colocado por el Ministerio de Cultura a la vera de la carretera que va de Trujillo a Huanchaco. Este camino ubicado entre las ruinas, atraviesa la pista, dirigiéndose hacia el mar, hacia una antigua plaza chimú ubicada en una explanada sobre un promontorio, donde se encuentra la iglesia San José, solitaria edificación mandada erigir en 1876 para que sirviese de estancia o «pascana» durante las bajadas procesionales quinquenales de Nuestra Señora Candelaria del Perpetuo Socorro, patrona de Huanchaco, en su recorrido hasta Trujillo.

Esa ubicación no es gratuita, como gratuita no fue la premura de la iglesia católica por instaurar el culto mariano que diluyese las creencias nativas. Veamos cómo esta historia se va eslabonando. Prosigue Valle:

Según los ancianos de Moche y Huanchaco, ellos lo reconocen como «camino del rey» (...) por ese camino salía el Rey a la orilla del mar (...) nuestros abuelos y nuestros padres han conservado la costumbre de echar brazas a las orilla del mar al mismo tiempo que rezaban algunas oraciones (católicas) con el objeto de ahuyentar la espesa neblina y cualquier tempestad que pudiera poner en peligro la vida de sus parientes que se encontraban pescando o viajando en al mar (...) Probablemente esta versión representa una remota y débil supervivencia del gran ceremonial que al Rey Chimú le tocó cumplir en la orilla del mar para fines similares. Entonces el Rey Chimú debió concurrir en procesional desfile 
conforme a su alta investidura, razón por la cual llega a nuestros días el recuerdo de que por este camino iba el Rey al mar. (2010, pp. 78-79).

Finalmente y para redondear el tránsito que se debió seguir en esa particular ceremonia de fecundidad de aguas dulces y saladas, termina:

Con relación a este camino chimú que llegó al canal El Milagro Alto, Rodríguez (1972, p. 105) considera que está relacionado con la llegada de las aguas de avenida en verano y a los trabajos de cultivo intensivo que se practicaba en las hoy desérticas tierras de Pampa La Esperanza. Entonces el rey Chimú, debió concurrir también en procesional desfile por este camino hasta el punto en que se unen los canales para recibir las aguas. (2010, pp. 79-80)

Otra de nuestras fuentes (Prieto, 2011) nos precisa respecto a esta virgen huanchaquera:

En muchos casos hubo en realidad una yuxtaposición de cultos, reemplazando antiguas divinidades andinas por sus semejantes católicos, lo cual se basaba en el género, en la coincidencia de las fechas de las celebraciones, en las semejanzas de los poderes metafísicos, etc. Así, los indígenas asociaron rápidamente la idea de una divinidad femenina en la religión católica y la relacionaron con el culto a la tierra (pachamama) y el mar (mamacocha). (p. 196)

El mismo Prieto precisa el emplazamiento de la iglesia San José con respecto a su funcionalidad:

Cabe destacar que este promontorio rocoso es un referente geográfico en las planicies desérticas al norte de Huanchaco (destacando su altura y color blanco) y cerca del mismo existe una asentamiento chimú tardío, mientras que en las faldas mismas del promontorio se ubicó un cementerio de la misma cultura (...) En otra ocasión hemos enfatizado también el rol que tuvo este promontorio en la organización y control de los campos y sistema de irrigación estatales Chimú ubicados en los alrededores del cerrito. (2011, p. 202).

El ciclo de la fertilidad chimú es un ciclo del eterno retorno, aguas saladas con dulces se alimentan y retroalimentan: las aguas dulces son portadoras de nutrientes que aumentan la biodiversidad de nuestros mares (los huanchaqueros aprecian en esas épocas la abundancia de las mejores especies: corvinas, robalos y cojinovas atraídas por las nutrientes del agua dulce). No nos olvidemos que este ciclo del mar al evaporarse y cruzar los picos cordilleranos, provoca las lluvias que regresan a sus aguas convertidas en caudalosos ríos de verano, obedece a los fenómenos climatológicos que rigen nuestro Mar de Grau. Finalmente, el acotado estudio de Prieto sobre los orígenes, ubicación y memoria colectiva de la virgen huanchaquera, nos precisa:

La fiesta anual de la Virgen Candelaria de Huanchaco guarda entonces dos trasfondos articulados en torno a la fertilidad (...) Si nuestras interpretaciones son correctas, entonces se puede concluir que dicha fiesta está íntimamente ligada a la fertilidad del mar y la tierra y al bienestar de la comunidad de pescadores garantizando su accesos a fuentes de alimento. (2010, p. 204) 


\section{La interpretación semiótica}

Hecha la descripción, pasaremos al análisis axiológico de dichos contenidos, para terminar con el uso que a este traje se le dio, a detallar el vínculo existente entre el soporte textil, la identidad del portador y su manejo corporal, y quiénes fueron los destinatarios de este mensaje, es decir, de los diversos niveles y aspectos comunicativos que lo convierten en un verdadero instrumento de manejo del poder y en un documento transmisor de la ideología de los Chimú, esto es, del metalenguaje y el contenido simbólico que de él se desprende. En síntesis, hemos abordado este estudio desde una perspectiva epistemológica diferente, manejando y analizando el traje como un texto, como soporte de un documento informativo portador de lógicas y categorías propias de esa cultura, en la certeza de que su entramado es un guión para el oficiante, un contenedor de signos portadores de una ideología organizados en una sintaxis precisa para dirigir mensajes a los fieles, al mismo tiempo que relacionándolo con usos y costumbres locales actuales de antigua data, a todo lo cual le damos una lectura novedosa que nos permita abrir un nuevo campo temático interpretativo. Pensamos que para interpretar la estructura del pensamiento andino y su cosmología, no basta el conocimiento académico tradicional al que estamos acostumbrados, por lo que buscamos perspectivas y ópticas de análisis que sean intrínsecas a él y otras que se manejen bajo parámetros y categorías propias, aquellas sobre las cuales no solemos reparar, las que lo rigieron y siguen rigiendo en gran medida a parte de este pueblo andino actual, y que no son definitivamente las que manejamos en centros de estudios universitarios y medios urbanos.

Tratándose este de un tema novedoso, nos permitiremos hacer mención del interesante trabajo realizado por la antropóloga suiza Genevieve Herold a propósito de las hermosas alforjas de Chota, Cajamarca (Herold, 1995) por ser el único que aborda el tema textil intentando descubrir en él un sistema de comunicación. Entre los años 1991 y 1992. Herold hace un trabajo de campo entre las tejedoras rurales de Cuyumalca, Chota, atraída por la belleza de sus alforjas (palabra de origen árabe que se da a una prenda de uso muy común en la zona rural de la Costa norte y Cajamarca) e intenta descubrir a través de esta pieza de vestuario mestiza y de su iconografía mestiza también, las normas de composición del espacio decorado y de los saberes técnicos (estos últimos, así como el uso del telar a cintura, son 100\% originarios), sin llegar a resultados claros, y pese a que la investigadora auscultó campos sémicos del entorno y sociales, no encuentra respuesta a sus incógnitas, como si algo en el camino se hubiera roto, como si una autonomía funcional de los motivos hubiera desprendido significantes de significados. Le faltó muy poco, debió ampliar su campo de investigación de otros significantes culturales más allá del hic et nunc. Hay que agradecerle, sin embargo, aunque lamentemos que nunca publicase su trabajo en el Perú, porque abrió un nuevo camino de investigación que no debe acabar. Este trabajo es un intento de proseguir por esa ruta.

Tenemos entonces, que el mundo andino presenta fórmulas diferentes de concebir el mundo y de producir conocimiento y es en la búsqueda de ese sentido que hemos desagregado la estructura física del traje y analizado sus cuatro niveles, hemos decodificado el contenido de la secuencia sintagmática o descriptiva de los significantes a través de los análisis numerológico, direccional, iconográfico y cromático para pasar a describir el manejo de la astronomía al servicio del ecosistema y sobre la cual se construye el campo semántico que sostiene en su narrativa toda la axiología o cosmovisión, la simbología, el meta discurso. 
Hay que considerar que la singularidad del pensamiento cósmico de los antiguos peruanos obedece a lo particular de su naturaleza cuyo frágil ecosistema debe ser tratado bajo ciertos parámetros para que la vida y la civilización prosperen. Este pensamiento basado en el conocimiento exacto de los astros con el que manejaron esta compleja naturaleza concebida como complementariedad territorial, se construye como una línea continua desde los inicios y es compartida por todas sus culturas a lo largo de su territorio y en todos los tiempos. Es oportuno mencionar que la cruz cuadrada o constelación de la Huillka Chackata bordada en el centro de los paneles del traje, se encuentra ya grabada en piedra en la celda de las vigas ornamentales de las galerías de las columnas de la pirámide mayor en el templo del Lanzón en Chavín de Huantar, 1200 años antes de la confección del traje.

Por consiguente, para sobrevivir en un ecosistema así de complejo, con una muy pródiga pero contradictoria naturaleza que debe ser manejada con cuidado, se requiere de un conocimiento total de la astronomía y un manejo holístico de los recursos para lograr los mejores resultados en la agricultura, tan dependiente de un recurso hídrico proveniente de fuentes variables y aleatorias que rigen nuestro océano: la corriente fría de Humbolt, la corriente cálida del Niño, el anticiclón del Pacífico y los vientos alisios enfrentados a la cordillera, los cuatro fenómenos climatológicos que crean este particular ecosistema donde los fértiles valles costeros rodeados de desierto, se nutren de las aguas evaporadas del mar que se elevan por sobre los Andes y desde allí se precipitan de las alturas convirtiéndose en los ríos que riegan ese desierto en un circuito de interdependencia total.

Es de allí que surge la necesidad de una ritualidad que marque pautas en el tiempo y en el espacio. Claramente para los chimú, la fertilidad de la tierra depende del ciclo de evaporación del mar. Prueba de ello es que dentro de su red de caminos, el gran ritual debe haberse hecho en una gran caminata hacia el este para ver la primera venida de aguas que anuncia la primera cosecha, donde se hallan los campos de siembra también rituales para proseguir luego hacia el oeste, al océano. Podemos imaginar en el mes de febrero, al Señor de Chimú así enjaezado con este espléndido traje que contenía escondidas a la vista de cualquier mortal la base reticulada o primer soporte textil del traje, representación de las redes o instrumentos de pesca que simbolizan la interacción del mar / tierra, la fecundidad de este binomio, y sobre ella las directivas de siembra, llevado primero en andas respaldadas por el tapiz perdido del cual solo quedan vestigios, desfilar con toda su magnificencia por el camino sagrado que une las aguas del mar con las dulces de los canales que permiten la fertilidad en la costa y alimentan el mar, para presidir la ceremonia de la primera siembra o siembra temprana cuyo momento culminante se daba durante el cenit.

Y este ritual debe haber sido tan importante que permanece en la memoria colectiva de su pueblo y fue reemplazado por ciertas fiestas patronales católicas a través de las cuales los actuales chimús continúan solicitando protección a su nueva deidad, la Virgen Candelaria del Socorro de Huanchaco, cuya capilla fue erigida allí por donde transitó el dicho Señor de Chimú. 


\section{Conclusiones}

El traje del Señor de Chimú ha salido de su vitrina y ha cobrado vida nuevamente para mostrarnos su singularidad, su categoría sagrada, pues este traje es una waka, un lugar sagrado, un centro ceremonial en sí mismo como existen físicamente los recintos o edificaciones religiosas o geográficas, cuya textualidad es una ontología contenedora de significantes organizados a través de una numerología que incluye no solo un calendario agrícola completo, lo cual está clarísimo, sino una compleja estructura y un sofisticado metadiscurso manejado por su portador a través de su esplendor manifiesto y del ocultamiento de lo sagrado, símbolos que solo él conoce y puede transmitir, es decir, hecho para establecer un diálogo entre el oficiante y los dioses para ser transmitido a su pueblo durante una particular ceremonia en el momento más importante del año: la venida de aguas dulces que se juntan a las salada y la primera cosecha en el mes de febrero.

No somos matemáticos y en ese sentido no nos atreveríamos a efectuar aseveraciones certeras, pero sí advertimos comportamientos que podrían acercarnos a valores o variables que encajarían dentro de una teoría de la singularidad, a funciones particulares que obedecerían a un ritmo que podría ser el del calendario lunar, puesto que la camisa tiene 24 divisiones, 32 el faldellín y 12 el turbante, considerando alguna forma de pensar primigenia de los antiguos peruanos que se nos escapa, para representar un ordenamiento cósmico, una racionalidad que puede no ser simétrica. Podría. Al respecto no hay que pronunciarse, más bien dejar abierta la posibilidad de conjugar el manejo numérico a especialistas matemáticos para que escruten posibles respuestas.

Es innegable, eso sí, que el traje trasciende su categoría de pieza histórica y museística para convertirse en un patrimonio invaluable material e inmaterial, en una pieza cuyo análisis nos podría dar muchísimos más indicios que los que someramente hemos encontrado en este estudio, por lo que habría que seguir explorando sus nexos con el presente, rastreando los resquicios donde el pasado que permanece se mezcla con un presente que parece tomar otros rumbos. El traje, además, se hace presente, nos llega al presente no solo para transmitir sus contenidos, sino para ligarnos a un linaje que los trujillanos bien podrían instalar en su presente de diferentes maneras y no solo académicas, pues no nos olvidemos que son los actuales pobladores de Huanchaco quienes han mantenido presente su memoria dándole nueva vida, ya sea a través de su testimonio y memoria colectiva, o del culto de la Virgen Candelaria del Socorro, como de «La leyenda del camino del rey llegando al mar», situación que no deja de sorprendernos considerando que Trujillo es una ciudad básicamente criolla. Mencionaremos el caso del Inti Raymi en el Cusco como el ejemplo más saltante de traer el pasado al presente, y con éxito. 


\section{Referencias}

Arnold, D. \& Espejo, E. (2013). El textil tridimensional: la naturaleza del tejido como objeto y como sujeto. La Paz: ILCA Plural Editores.

Brugnoli, P., Hoces de la Guardia, S., Jelvez, P., \& Gomez, T. (1997). Fertilidad para el desierto. Un traje ceremonial chimú. Costa norte de los Andes Centrales, siglos XII-XV. Santiago de Chile: Museo Chileno de Arte Precolombino.

Campana, C. (2012). Memorias del viento frente a Chan Chan en Chan Chan, ayer y hoy. Lima: Ediciones SIAN, Horizonte.

Herold, G. (1995). Las alforjas de Chota, tissage, exchanges et portage dans les Andes de Cajamarca, Perou. Université de Neuchatel. Insitute D’Ethnologie, Neuchatel. Recuperado de http://doc.rero.ch/record/209443

Museo Chileno de Arte Precolombino (noviembre 2005 - mayo 2006). Laberintos de un traje sagrado. Santiago de Chile

Nuñez, G. (2015). Culturas orales y culturas escritas. Lima: Departamento Académico de comunicaciones PUCP.

Palma, J. \& Baixas, I. (1986). Estudio de tres piezas que conforman un atuendo funerario. Revista Chungara 16-17, 381-394.

Prieto, G. (2011). Las fiestas anuales y quinquenales de la Virgen Candelaria del Socorro de Huanchaco: expresión religiosa de los pescadores de la costa norte del Perú. Arqueología y Sociedad, 23, 193-222.

Reid, J. (1988). Textiles en Chimú. Colección Arte y Tesoros del Perú. Lima: Banco de Crédito del Perú.

Rodríguez, V. (1970). Irrigación prehistorica en el valle de Moche. XXXIX Congreso de Americanistas. Instituto de Estudios Peruanos. Lima.

Rodríguez, V. (1972). Caminos prehispánicos norperuanos (estudio preliminar). I Congreso Peruano de Arqueología,

Lima. Rowe, A. (1984). Costumes and featherworks of the Lords of Chimor. Washington D. C.: Textile Museum.

Rowe, A. (1989). Textiles Chimú en Textiles Milenarios. Lima: AFP Integra.

Valladolid, J. (1993). Agroastronomía andina en Cultura Andina Agrocéntrica - Proyecto Andino de Tecnologías Campesinas. Lima: PRATEC.

Valle, L. (2010). Rituales en torno al camino ceremonial en Chan Chan. Revista Pueblo Continente 21, 73-82. 
